\title{
Dos bienales, dos hemisferios, dos tendencias. Las Bienales de Venecia como pretexto para una reflexión
}

Two biennials, two hemispheres, two trends. The Biennials of Venice as a pretext for reflection

\author{
Alessandro Masoni \\ Masoni Architetti (Italia) \\ Univesidad Tecnológica de la Habana (Cuba)
}

Masoni, A. (2019). Dos bienales, dos hemisferios, dos tendencias. Las Bienales de Venecia como pretexto para una reflexión. Revista de Arquitectura (Bogotá), 22(I). II8-129 https://doi.org//0.14718/ RevArq.2020.2257

Arquitecto, Universidad de Florencia, Italia. Magíster en Arquitectura, Universidad de Florencia, Italia.

Doctorado, Universidad de Florencia, Italia. http://www.masoniarchitetti.it/ (D) https://orcid.org/0000-0002-7572-7I2X arch.alessandromasoni@gmail.com

\section{Resumen}

La Bienal de Arquitectura de Venecia es uno de los eventos más importantes del mundo para la arquitectura y el debate disciplinario. Dos de las pasadas bienales, por sus marcadas diferencias y oposiciones, son utilizadas como pretexto para una reflexión crítica sobre dos tendencias que podrían definirse "hemisféricas": la que tuvo como curador al holandés Rem Koolhaas, en 2014, y la curada por el chileno Alejandro Aravena, en 2016. La bienal de Koolhaas presentó una valiosa investigación histórico-enciclopédica, de la que emanaba una latente inquietud generada por el meticuloso desmantelar la arquitectura a la búsqueda de sus piezas básicas. La bienal de 2016, la primera curada por un arquitecto del "hemisferio sur" del mundo, intentaba, por otro lado, mostrar en su amplitud un panorama de trabajos socialmente más comprometidos, pero, a su vez, sesgaba con claridad hacia un exceso de pragmatismo. Posiblemente, valorar en una reflexión comparativa estos dos enfoques puede restituir más nitidez al pensamiento y a la acción, gracias a la síntesis entre posiciones antitéticas que, por sí mismas, parecen no abrazar el amplio espectro de las posibilidades y de las necesidades disciplinarias contemporáneas.

Palabras clave: Alejandro Aravena; composición; diseño arquitectónico; investigación proyectual; Premio Pritzker; proyecto arquitectónico; Rem Koolhaas

\begin{abstract}
The Venice Architecture Biennale is one of the most important events in the world for architecture and for the disciplinary debate. Two of the past Biennale - the one curated by the Dutchman Rem Koolhaas in 2014 and the one curated by the Chilean Alejandro Aravena in 2016 - with their marked differences and oppositions, are used here as a pretext for a critical reflection about two trends that could be defined as "hemispheric". The Koolhaas Biennial presented a valuable historic-encyclopedic research, which emanated a latent concern due to the meticulous dismantling of architecture at its basic pieces. The 2016 Biennal, the first Biennial curated by an architect of the world's "Southern hemisphere", tried to show a broader overview of more socially committed works, but in turn it seemed clearly biased by an excess of pragmatism. Assessing these two approaches in a comparative reflection, could possibly reinvigorate the thoughts and actions of architects, through the synthesis of antithetical positions that, by themselves, do not seem to embrace the full spectrum of contemporary disciplinary possibilities and needs.
\end{abstract}

Keywords: Alejandro Aravena; composition; architectural design; project research; Pritzker Prize; architectural project; Rem Koolhaas

\section{Introducción}

El artículo presenta los resultados de una investigación desarrollada dentro del marco del tema de Problemas sociales de la ciencia y de la tecnología, preparada por la Universidad Tecnológica de La Habana (Cuba). Parte de dicho material de investigación confluye en el presente artículo.

\section{Génesis de la reflexión}

El interés personal en la profundización de los diversos matices que definen el iris de declinaciones disciplinarias, alimentado por el aflato cosmopolita de muchas experiencias, culturas y contextos experimentados de primera mano, encuentra en las Bienales de Arquitectura de Venecia, con cadencia regular, un vivero relevante de confrontación, de análisis y de reflexión de alcance global.

El encuentro con el contexto cubano, acontecido poco después del hito histórico de una curaduría latinoamericana de una Bienal de Venecia en 2016, se ha revelado como un provechoso estímulo para desencadenar un razonamiento sobre el tema de las diferentes declinaciones de la visión disciplinaria en diferentes macrocontextos.

La ocasión para enfrentarse directamente con este tema, a través de un análisis personal que pueda profundizar algunas inspiraciones, se ha presentado al tener que desarrollar una investigación sobre las problemáticas sociales de la técnica, la tecnología y la ciencia, analizadas como herramientas de conocimiento y fenómenos sociales. La finalidad del ejercicio propuesto por la universidad cubana era despertar la conciencia de los científicos y de los técnicos acerca del impacto de sus acciones sobre la naturaleza y el contexto humano en el cual se desarrollan. Orientar la reflexión a la componente de responsabilidad social que, inevitablemente, los intelectuales y los técnicos asumen, constituyó un impulso que, ya por sí mismo, marcaba una diferencia sustancial en el enfoque a la educación y a la disciplina con el de los contextos italiano y europeo.

La arquitectura reside, por su misma naturaleza disciplinaria, en el borde entre ciencia y sociedad, y toca, a la vez, técnica, tecnología, arte, política y ciencias sociales. Todos estos componentes se encuentran siempre, muchas veces de forma 
inconsciente para los arquitectos, profundamente entramados en una red inextricable que, según como se mire, resalta unas $u$ otras matrices. Esto convierte la arquitectura en una disciplina extremadamente valiosa para realizar reflexiones de gran amplitud, pero conlleva grandes complicaciones a la hora de definir campos de análisis circunscritos y, al mismo tiempo, prolíficos.

La clave para un análisis circunstanciado de más amplio alcance pudo encontrarse recurriendo a la memoria de las emociones despertadas por dos de las más interesantes Bienales de Venecia visitadas en los años pasados: la 14a Bienal de Arquitectura de 2014, curada por el arquitecto holandés Rem Koolhaas, y la 15a Bienal de Arquitectura de 2016, curada por el arquitecto chileno Alejandro Aravena. Esas dos muestras de arquitectura proporcionaban de forma explícita herramientas conceptuales, textos, ejemplos prácticos y reflexiones tecnológicas con hitos de gran agudeza. Además, en virtud de la proveniencia y de la relevancia de sus curadores, resultaban bien aptas para desarrollar el tema del valor característico asignado a la disciplina dentro de los relativos marcos culturales de gran escala. Las peculiaridades técnicas, sociales, tecnológicas, artísticas y humorales de cada bienal destacaban hasta, casi automáticamente, determinar un esbozo de esferas de influencias y de referencias sistémicas que se han definido, no tan atrevidamente, como "hemisféricas"1.

Parece apropiado, en conclusión, resaltar que, en virtud de su complementariedad, estos matices de diferentes concepciones disciplinarias pueden reforzarse mutuamente, ayudando a una siempre más necesaria visión holística y sinérgica de la materia, abierta sin perjuicio a los distintos componentes culturales qua van afirmando su presencia en el escenario global.

\section{Presentación del tema}

La Bienal de Arquitectura de Venecia puede ser considerada uno de los eventos más importantes del mundo para la disciplina, y una especie de sismógrafo del sector para el debate mundial. La Bienal de Arquitectura es solo uno de los eventos que la Fundación Bienal de Venecia organiza, y que en su totalidad abarcan por entero el mundo de las artes: artes plásticas, cinema, teatro, danza, música.

La primera Bienal de Arquitectura, de 1980, fue curada por el arquitecto, historiador y crítico de la arquitectura Paolo Portoghesi, y consagró el

1 De alguna forma, la referencia más cercana podría ser al "North-South Divide" y a las ideas de norte-global y sur-global. De todas maneras, en este texto se prefiere no hacerle referencia directa, por cuanto el concepto lleva implícito un papel y una actitud paternalista de Occidente. La intención es aquí investigar las diferencias como motor de conocimiento y crecimiento mutuo. adviento mundial del posmodernismo². Desde entonces dicha exposición ha marcado el paso de los logros y de los equilibrios globales de la disciplina.

El papel del curador de la Bienal de Arquitectura, a menos de pocos precedentes históricos en las primeras bienales, fue en general más enfocado a exhibir proyectos de arquitectos selectos, o de los propios curadores, que a utilizar la muestra para trazar líneas coherentes de reflexión a través de las obras (Baratta, 2014, p. 14). Por tal motivo, en 2014 la Fundación Bienal seleccionó al holandés Koolhaas, arquitecto y teórico de amplia experiencia y reconocimiento global, a fin de elevar el nivel conceptual y atractivo ${ }^{3}$ de la exposición de arquitectura gracias a un proyecto global de investigación coral, supervisado por el mismo curador. La elaboración expositiva y temática que él propuso fue muy interesante y bien concertada; no obstante, varios críticos y arquitectos salieron de la visita con no tan sutiles sensaciones de desasosiego y de inquietud. Tales sensaciones se han demostrado reveladoras en su paralelo con la bienal siguiente, en 2016, la cual marcó, por su parte, otro singular acontecimiento en la historia del evento, al asignar, por primera vez, la curaduría a un arquitecto latinoamericano: el chileno Alejandro Aravena. A diferencia de esta bienal, las curadurías siempre habían sido asignadas a arquitectos o críticos del hemisferio norte del mundo.

El proyecto curatorial de Aravena se enfocó profundamente en mostrar acciones arquitectónicas comprometidas con contextos complejos y difíciles, que, por primera vez, pudieron resaltar en número y en una colocación disciplinaria mucho más amplia que lo que las bienales anteriores habían dejado percibir.

El comparativo entre estas dos bienales y sus temáticas parece capaz de revelar y exaltar la presencia de dos tendencias en acción, que bien podrían definirse, ya sea física o metafóricamente, como "hemisféricas". De estas tendencias, la que se explicita en la curaduría de Koolhaas, y que, por lo general, corresponde al hemisferio "norte" del globo, ha gozado de mucha más visibilidad y de muchos más recursos de la otra. Paradójicamente, dicha tendencia parece afligida por un legado

2 Bienal de 1980, curador Paolo Portoghesi: La presencia del pasado. Esta fue la bienal del Teatro del Mundo de Aldo Rossi y de la "Estrada Novísima", que abrió un debate intenso, deviniendo un símbolo del movimiento posmodernista. Aquí expusieron: Frank O. Gehry, Rem Koolhaas, Arata Isozaki, Robert Venturi, Franco Purini, Ricardo Bofil, Christian de Portzamparc, etc. La bienal, en principio, no mantuvo estrictamente su cadencia bienal, que se establece definitivamente con la a Bienal de 1996, con Hans Hollein como curador. Esta bienal se titulaba El arquitecto como sismógrafo-sensores del futuro.

3 Los visitantes de la bienal de 2014 fueron 228.000, con un incremento del $28 \%$ respeto a la edición anterior. Además, la organización decidió, a partir de esta bienal, extender el periodo de abertura a 6 meses, frente a los 3 habituales. La bienal de 2016 atrajo a 260.000 visitantes, con un ulterior incremento del $14 \%$. 
de desvío y de crisis disciplinaria, como confirman algunas de las críticas a esta misma bienal de $2014^{4}$.

Al contrario, la primera bienal curada por un arquitecto del "sur" del mundo pasó dejando huellas de pragmatismo, que transmitieron un real sentido de identidad y de desafío que, por algunos rasgos, parecen poder compensar esa crisis de valores; no obstante, esta bienal fue, a su vez, criticada por ensanchar demasiado los límites de la acción, hasta correr el riesgo de pisar utopías autoindulgentes y aniquilar el valor artístico de la disciplina, pues ofreció solo meras sugestiones, y no verdaderas soluciones, para los problemas planteados ${ }^{5}$.

Entre estos dos polos quizás pueda delinearse una lectura por tesis y antítesis que pueda trazar las bases para una reflexión global sobre los compromisos disciplinarios.

\section{Una observación necesaria}

Ambos curadores de las bienales - Rem Koolhaas, por la 14a Bienal de 2014, y Alejandro Aravena, por la 15a Bienal de 2016-, son personajes altamente mediáticos. Los dos son ganadores del premio Pritzker ${ }^{6}$, demuestran una gran maestría a la hora de utilizar los medios de comunicación para difundir sus visiones y, sobre todo, para promover sus propias imágenes. Ambos tienen seguidores y detractores, que defendieron o reprobaron sus bienales. Es cierto que con sus firmas - OMA, la de Koolhaas, y Elemental, la de Aravena-, pertenecen a la élite de la disciplina, y también es probable que sus actitudes profesionales se destaquen de las tendencias sostenidas en sus curadurías para las bienales. De todos modos, el intento de esta reflexión crítica es enfocarse en el contenido de las bienales alejándose del relativismo y de la retórica para destacar juicios de mérito constructivos y progresivos. Las curadurías y las obras expuestas servirán para observar las especificidades de las tendencias que se han revelado como paradigmáticas.

\section{Las dos bienales}

La bienal de 2014, curada por el holandés Rem Koolhaas, se titulaba Fundamentals. Sobresaliente fue la exhibición Elementos de Arquitectura, una tabla periódica histórico-científica de

4 Para un rápido panorama de las críticas a esta bienal, véanse: Taylor-Hochberg (2014) y Stott (2014). Quizás, la más aguda síntesis de las razones de aquellas sensaciones de desasosiego se encuentra en las palabras del arquitecto y crítico Peter Eisenman: según él, Koolhaas fue "desmontando la bienal y con ella toda la arquitectura". Citado en el artículo de Guy Horton (2014, p. III).

5 Para un rápido panorama de las críticas a esta bienal, véanse: Chatel (2016) y Cheng (2016), la cual se expresa de esta forma: "por una Bienal que aspiraba a pisar tierras de alto valor moral, Aravena ha dejado los críticos con sentimientos molestos" (Cheng, 2016, p. IV).

6 El Pritzker es uno de los premios de arquitectura más prestigiosos; Koolhaas lo ganó en 2000, y Aravena, en 2016 (el mismo año de la bienal). los principales elementos arquitectónicos: muros, techos, balcones, escaleras, ascensores, puertas y pisos, entre otros, y cuyo intento era, como fue declarado por el curador mismo, "mirar bajo un microscopio a los elementos fundamentales de nuestros edificios, utilizados por todos los arquitectos, en cualquiera lugar, en cualquier tiempo" (Koolhaas, 2014, p. 193) (figura 1).

Esta sección era acompañada por otras exhibiciones, como Monditalia, que miraba a Italia como un país en difícil equilibrio entre el caos y la realización de su potencial, y Absorbing Modernity 1914-2014, que involucraba las pequeñas embajadas arquitectónicas de cada nación presente en el predio de la bienal, para representar las vías por las que sus países habían absorbido la modernidad (Koolhaas, 2014).

La bienal de 2016, curada por el chileno Alejandro Aravena, fue titulada Reporting from the front, y presentó como su temática principal una panorámica global de experiencias ejemplares de arquitecturas que desafían los problemas sociales contemporáneos.

Mientras que la bienal de 2014 tenía un enfoque "enciclopédico", y, como muchas bienales anteriores, parecía deplorar el presente, la bienal de 2016 presentó una vigorosa pragmaticidad y un fuerte carácter experimental, comprometida con el presente ${ }^{7}$ y enfocada en "investigar más explícitamente como y donde hay tendencias que van en dirección diferente, hacia una renovación [...] buscando mensajes esperanzadores [y] resultados que someter a un juicio crítico" (Baratta, 2016, p. 14) (figura 2).

\section{Metodología}

Este texto no pretende ser una verdadera investigación científica positivista, sino una reflexión ordenada con raíces sólidas y substanciadas. El ámbito de esta reflexión se presentó por sí mismo bien circunstanciado, gracias a la utilización de las dos bienales como incentivo para fundamentar el razonamiento de una forma apropiada al propósito.

La reflexión, más de actualidad que histórica, se hizo a partir de la consulta y la interpretación de informaciones provenientes de fuentes primarias. Se recopilaron las notas de las visitas a las dos exposiciones y se estudiaron minuciosamente los catálogos de las Bienales de Venecia. Los catálogos de las bienales reportan el propósito programático de los curadores, con textos originales de ellos mismos y de la institución Bienal de Venecia, que, a través de las palabras de su presidente, Paolo Baratta, presenta las motivaciones de la

\footnotetext{
7 De los 88 participantes en la bienal de 2016, 50 exponían por primera vez y 33 tenían menos de 40 años de edad (Frearson, 2016).
} 
elección del curador y el objetivo general que se prefija esta importante entidad cultural italiana.

En los catálogos se documenta de forma ordenada el contenido de las muestras y se enumeran las muchas obras expuestas; a cada una de estas se dedican párrafos sintéticos de explicación de los aspectos conceptuales y disciplinarios primarios para los autores y los curadores. De igual forma, en dichos textos se citan, explícita o implícitamente, los motivos por los que fueron seleccionadas, y se da razón, al mismo tiempo, del objetivo de la curaduría y de los diferentes valores asignados a las obras. En el maremagno de las obras expuestas, hubo que dirigir la atención solo hacia algunos ejemplos emblemáticos, que fueron elegidos por su impacto emotivo a la hora de la visita a la bienal o que resultaron ganadores de premios de jurado. Fue una elección consciente, a la hora de redactar el texto, evitar de caer en ejemplos singulares, y utilizando, al contrario, los núcleos conceptuales de estas obras notables para generalizar temas sobresalientes.

De la misma forma, se eligió no mencionar las diferencias de escala al hablar de la "arquitectura", sino aceptar como definición de esta todas las actividades que abarca la acción de modificar el ambiente, desde la macroescala (urbana, de paisaje y de los edificios) al micronivel (detalles constructivos y de interiorismo).

En segunda instancia, gracias al abundante aparato de prensa que despierta este evento, se buscaron y se consultaron entrevistas y artículos de actualidad (sobre todo, artículos on-line, dada la distancia geográfica donde se ha desarrollado el trabajo) que permitiesen reconstruir la opinión de arquitectos y teóricos de varios países al momento del estreno de las bienales. De igual forma, debido a la secuencia temporal de los eventos, se buscaron las declaraciones o las reflexiones dentro de las entrevistas y de los artículos que dejasen rastros de paralelos entre las curadurías.

Consecuentemente con lo anterior, se estudiaron algunos textos de referencias sobre el pensamiento disciplinario de los dos arquitectos curadores de las bienales, Aravena y Koolhaas, y otros textos más genéricamente enfocados en el contexto teórico contemporáneo occidental y en las peculiaridades del contexto latinoamericano, menos conocido por el autor.

Resultó fundamental el respaldo de la visita personal a estas y muchas otras Bienales de Venecia anteriores y posteriores. Esto permitió leer las informaciones en un más amplio espectro temporal y desarrollar las reflexiones a partir de memorias personales y de las sensaciones que cada muestra transmitió en su despliegue. Gracias a la impresión emotiva que el "carácter"

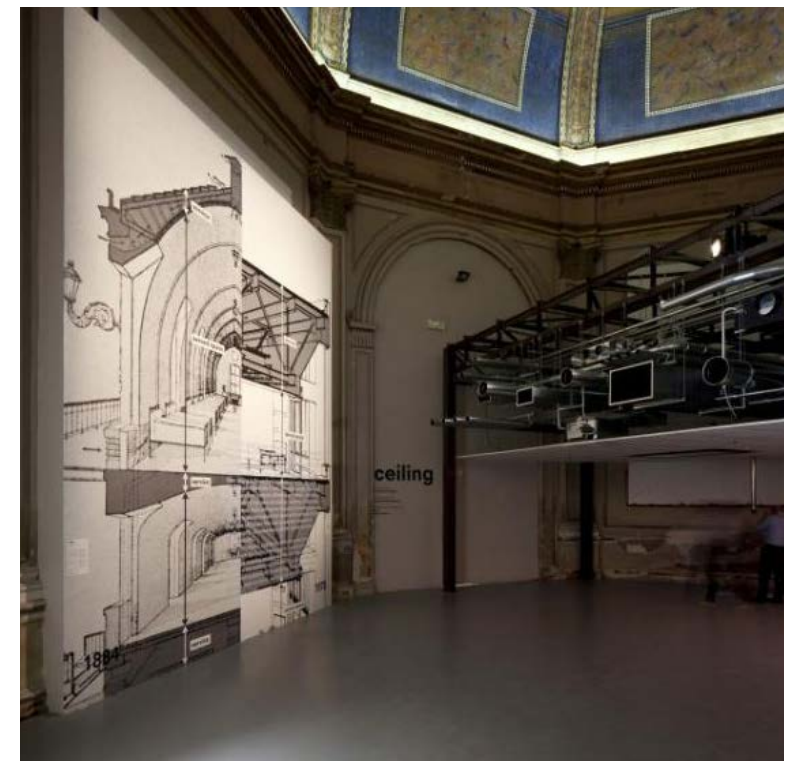

\& Figura 1. Entrada a la bienal de 2014. Sistema de falso techo técnico, como elemento de la arquitectura y ejemplo de las nuevas posibilidades tecnológicas. Es fuerte el contraste con la preexistencia histórica. Fuente: Galli (2014a) C

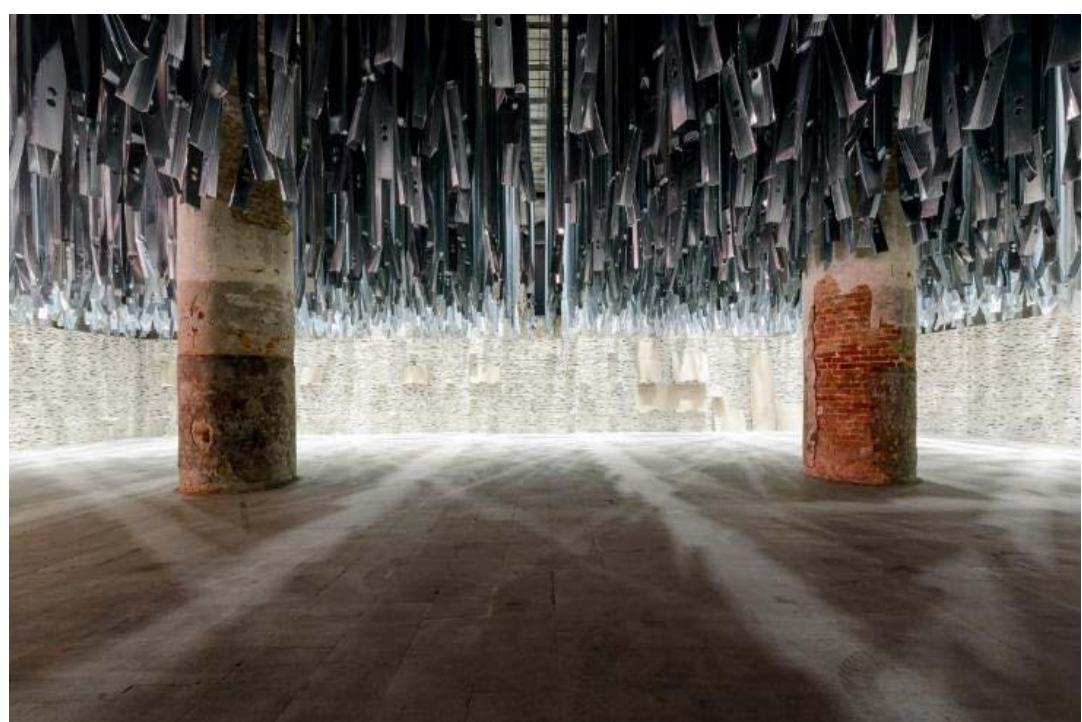

expositivo de estas dos bienales suscitó a la hora de visitarlas, muchas de las ideas confluidas en el presente artículo ya estaban formadas, y así se pudo desarrollar de forma casi natural los conceptos básicos que han constituido los aspectos fundamentales de la reflexión.

Por fin, todas las informaciones se procesaron a través de paralelos cualitativos y comparativos, que permitieron resaltar conceptos cardinales de diferenciación entre las aptitudes curatoriales, $y$, como se pretende resaltar en este texto, hitos fundantes de visiones disciplinarias diferentes y complementarias, que nos llevan a pensar en ellas como "hemisféricas". En cuanto a los textos básicos de referencia, se seleccionaron las temáticas notables. Los criterios de elección surgieron de forma casi espontánea, debido a la gran confianza que ha ido adquiriéndose en el ámbito de las bienales analizadas, y fue posible construir un proceso de escrutinio por tesis y antítesis que parece llevar a síntesis fundadas, y posiblemente progresivas, respecto a una discusión que es esencial mantener viva en lo disciplinar.
(A) Figura 2. Entrada a los arsenales de la bienal de 2016. La instalación recuperó los materiales empleados en la bienal de arte de 2014.

Nota: es evidente la gran cantidad de material que fue utilizada, y que de otra forma se habría perdido.

Fuente: Avezzù (2016) (c). 


\section{Resultados}

\section{Descontextualización-contexto}

La primera diferencia entre las dos bienales, y quizás la más grande, puede hallarse en las distintas relaciones que teje cada una de ellas con los contextos en los que se desarrolla la acción de la arquitectura.

En Elementos de arquitectura, Koolhaas practica una operación de substancial abstracción aplicada a la "arquitectura" entendida como construcción virtualmente indiferente al contexto en la que se construye. No se presentan experiencias contextualizadas, sino que se extraen las partículas elementales utilizadas por "todos los arquitectos, en todos los lugares, en todos los tiempos" (Koolhaas, 2014, p. 193) dejándolas flotar en un espacio arquitectónico diseccionado y artificial. No se destaca ningún nexo con un "lugar" ni se destaca relación alguna con problemáticas humanas que no sean puramente ergo-

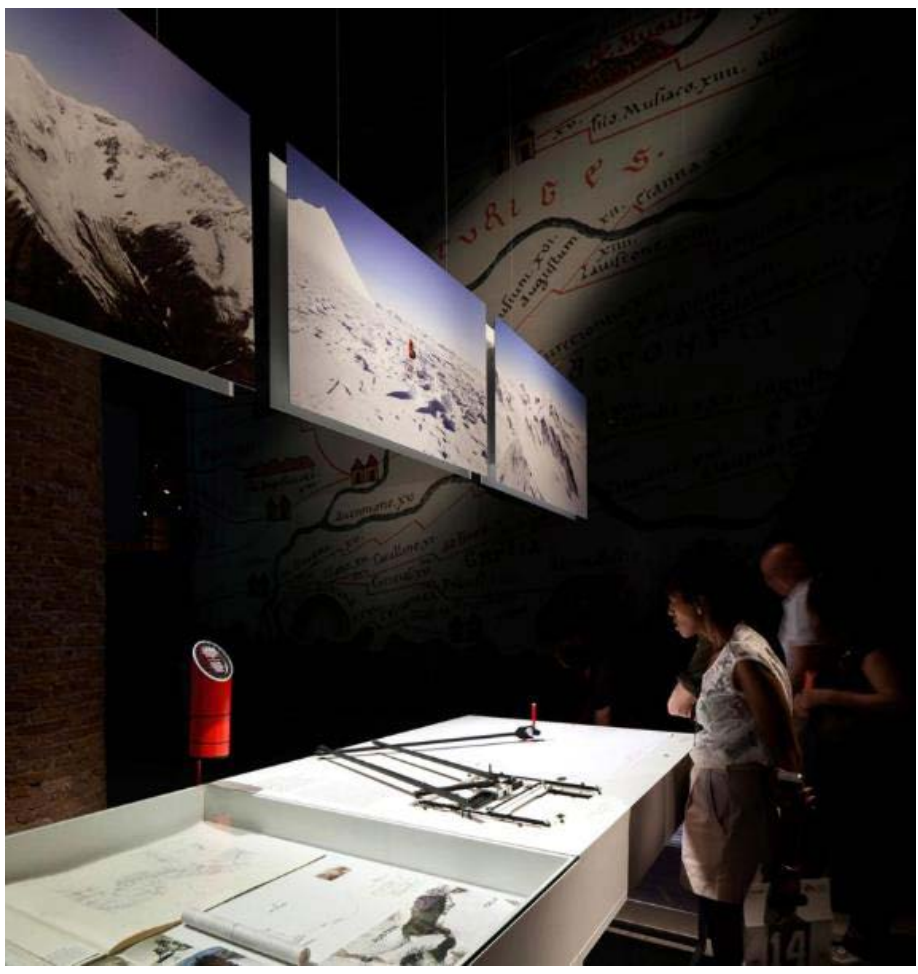

nómicas. Esta operación, valiosa en términos de investigación conceptual, resulta abstracta hasta el punto de ignorar las necesidades culturales y contextuales que, de hecho, generaron las características técnicas de muchos de tales objetos; además de la sección "Elementos", por toda la bienal de Koolhaas, en los pabellones nacionales como en "Monditalia", el nexo con los contextos de las obras expuestas se revela eminentemente histórico, artístico y hasta "diagnóstico" y por lo general parece carecer del reflejo de la acción factual de construir arquitectura en un lugar "físi$\mathrm{CO}^{\prime \prime}$ socialmente caracterizado (figura 3).

La curaduría de Aravena, en 2016, se establece de forma casi completamente antitética, tratando de contribuir a la génesis de un paradigma que pasa, de forma casi brutal, "de un lugar visto en una dimensión metafísica, trascendente, poética a un lugar más corriente, más común, más cotidiano" (Aravena, 2002, p. 73), comprometido con la realidad medioambiental y social, (Zabalbeascoa, 2016; Vaisman, 2016). Si bien dicha relación contextual comprometida con la realidad medioambiental y social es, indudablemente, un valor, siempre más necesario para una sociedad globalizada en rápida mutación, el riesgo que se vio correr en varias obras expuestas en esta bienal es el de perder el aflato poético que define la arquitectura como arte (figura 4).

Aravena apela a la sencillez del pensar la arquitectura: "Arquitectura es dar forma a los lugares donde vivimos. No es más complicado que así, pero tampoco es más sencillo que así" (2016, p. 19). La elementalidad que, obviamente, lo es solo en apariencia, en cuanto se carga de inmediato de las dificultades derivadas de la confrontación con las condicionantes del contexto político, ideológico y cultural y con las operaciones técnicas que se deben realizar en un espacio y un tiempo específicos, no puede, a su vez, prescindir de una profundizada investigación científica y artística que tenga como objetivo trasmitir los valores culturales.
(A) Figura 3. Italian Limes-Folder. Es una reflexión más filosófica que geográfica, ambiental, o hasta legal, sobre qué cosa significa hoy en día una frontera. El nexo con el contexto es puramente intelectual y diagnóstico, y es representado con sensibilidad artística.

Fuente: Galli (2014b) @ .

จ Figura 4. Instalación de Al Borde-Dark Resources. Una reflexión económica sobre los recursos con los que se construye la arquitectura. A estos se añaden los "recursos oscuros", o medios disponibles que provienen de fuentes no convencionales. Fuente: Al Borde Arquitectos (2016) @ .

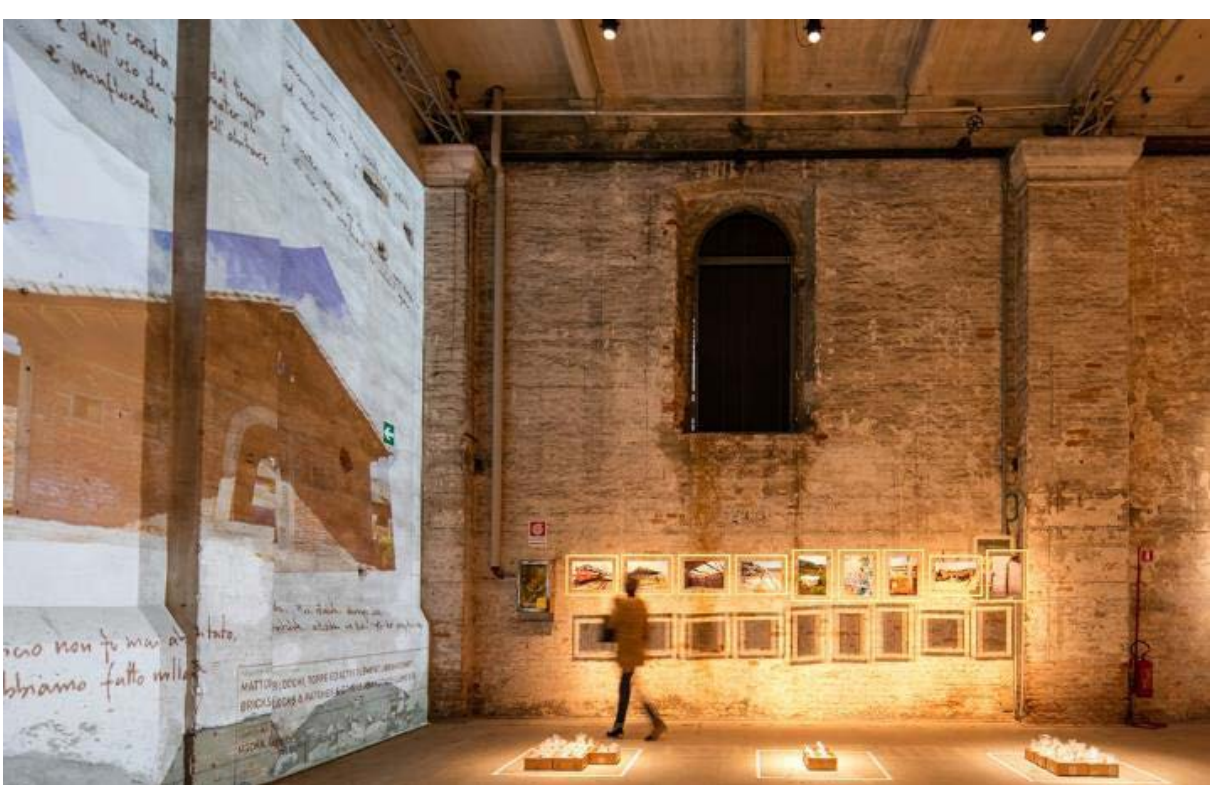


La relación con los lugares reales, con las personas y con sus necesidades materiales y espirituales requiere desafíos multidisciplinares. La arquitectura tiene que enfrentarse de tal forma a la política y a las fuerzas económica en juego. La disciplina no puede prosperar sin comprender la sociología, la antropología y la cultura de una sociedad; sin conocer el derecho que la limita, la ecología que define su sostenibilidad así como la ciencia y la técnica que la construyen; no obstante, la calidad artística de una arquitectura se define en el tiempo, que deja atrás muchos de los valores contingentes de sociedades en inevitable mutación, y por esto es indispensable una profunda reflexión sobre los elementos de permanencia con que la arquitectura misma se construye.

\section{Composición-proyecto}

Koolhaas parece abogar por un abandono del paradigma de proyecto, para destacar una concepción más puramente compositiva, concibiendo los fundamentos de la disciplina como un repertorio de elementos físico-conceptuales aptos para discretizar un elemento continuo, como una arquitectura, en muchos elementos singulares y variables, (figura 5).

Si bien "proyecto" y "composición" mantienen algunas relaciones relevantes en el campo del diseño arquitectónico, la diferencia entre ambos que se quiere aquí subrayar reside en la actitud frente al proceso creativo. Por su étimo, el proyecto tiene fronteras indefinidas. El acto de proyectar no es exclusivo de la arquitectura: se aplica en muchos ámbitos, y abarca, en el intento de desarrollar el proyecto, muchas disciplinas y esferas diferentes. Por el contrario, la composición pertenece, de forma casi exclusiva, al campo de las artes, como yuxtaposición ordenada de partes en armonía.

El reduccionismo aplicado por Koolhaas en su bienal presenta un abandono casi total de la complejidad proyectual, al reducir el valor definitivo del diseño a las relaciones formales entre los elementos individuales. Esta actitud autolimita el campo hasta llegar a vaciar la disciplina de su esencia proyectual, de su instinto visionario hacia el futuro. El riesgo es dejar atrás las componentes complejas y, sobre todo, como parece pasar en muchas arquitecturas contemporáneas del "hemisferio norte", el inevitable impacto social que cada acción proyectual tiene en cuanto acción cultural.

La bienal de 2016 marca otra antítesis en esta esfera. La exposición curada por Aravena resulta prioritariamente proyectual, hasta llegar a veces a desbordar en un excesivo pragmatismo. Según las mismas palabras programáticas del presidente de la bienal, la muestra de 2016 no está "interesada a la arquitectura como manifestación de un estilo formal, pero más bien como [...] herramienta de la vida social y política" (Baratta, 2016, p. 14).
La concepción del proyecto se amplía aún más allá de sus límites disciplinarios, abre su campo semántico a la totalidad de los procesos colectivos. El límite de esta posición opuesta es, a su vez, el hecho de caer en la trampa de una falsa actitud multidisciplinaria, que resulta dispersiva para los aspectos más puramente arquitectónicos. Las experiencias expuestas utilizan las herramientas arquitectónicas para restablecer una sinergia entre el ser humano, la sociedad y el medio ambiente, pero los resultados no siempre tienen la profundidad necesaria para definir hitos metodológicos o para emerger como ejemplos de permanencia (figura 6).

El enfoque casi experimental de las experiencias expuestas por Aravena se muestra capaz de enfrentarse a los problemas locales específicos sin dejar totalmente atrás la imprescindible escala global en la que se escriben todas las acciones contemporáneas (Fajardo \& Oliveros, 2015, p. XVII). Al mismo tiempo, tiene el evidente límite de que muchas de las experiencias expuestas parece que no logren trascender la escala técnica para anhelar al estatus de arte que rinde inmortal la gran arquitectura.

(1) Figura 5. Instalación (1) Elements. Un catálogo de los principales componentes: muros, techos, balcones, escaleras, etc., exhibidos como piezas de montaje de los edificios.

Nota: Más allá de la tecnicidad, se podía leer la intención de definir permanencias atemporales. Fuente: La Biennale di Venezia (2014a) C)

(1) Figura 6. Gabinete de $(7)$ arquitectura (Solano Benítez, Gloria Cabral, Solanito Benítez. Asunción, Paraguay).

Nota: obra ganadora del León de Oro a la Bienal 2016. El valor técnico-constructivo sublima en arquitectura. "La obra [...] está dedicada a nuestra gente, a todos los que tanto nos han enseñado" (Benítez, citado en Ultimahora, 2016, párr. 2).

Fuente: La Biennale di Venezia (2016a) (C).
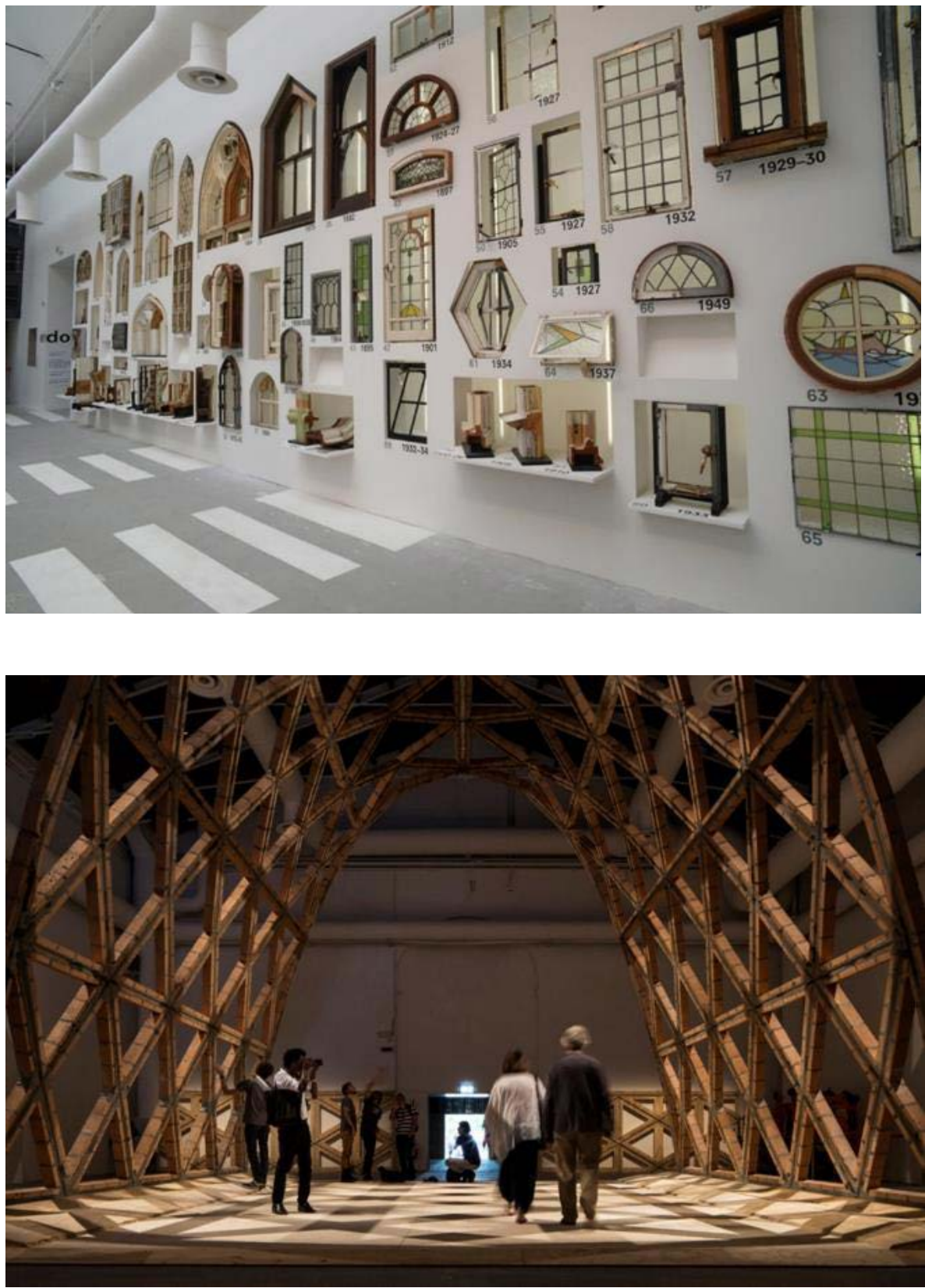

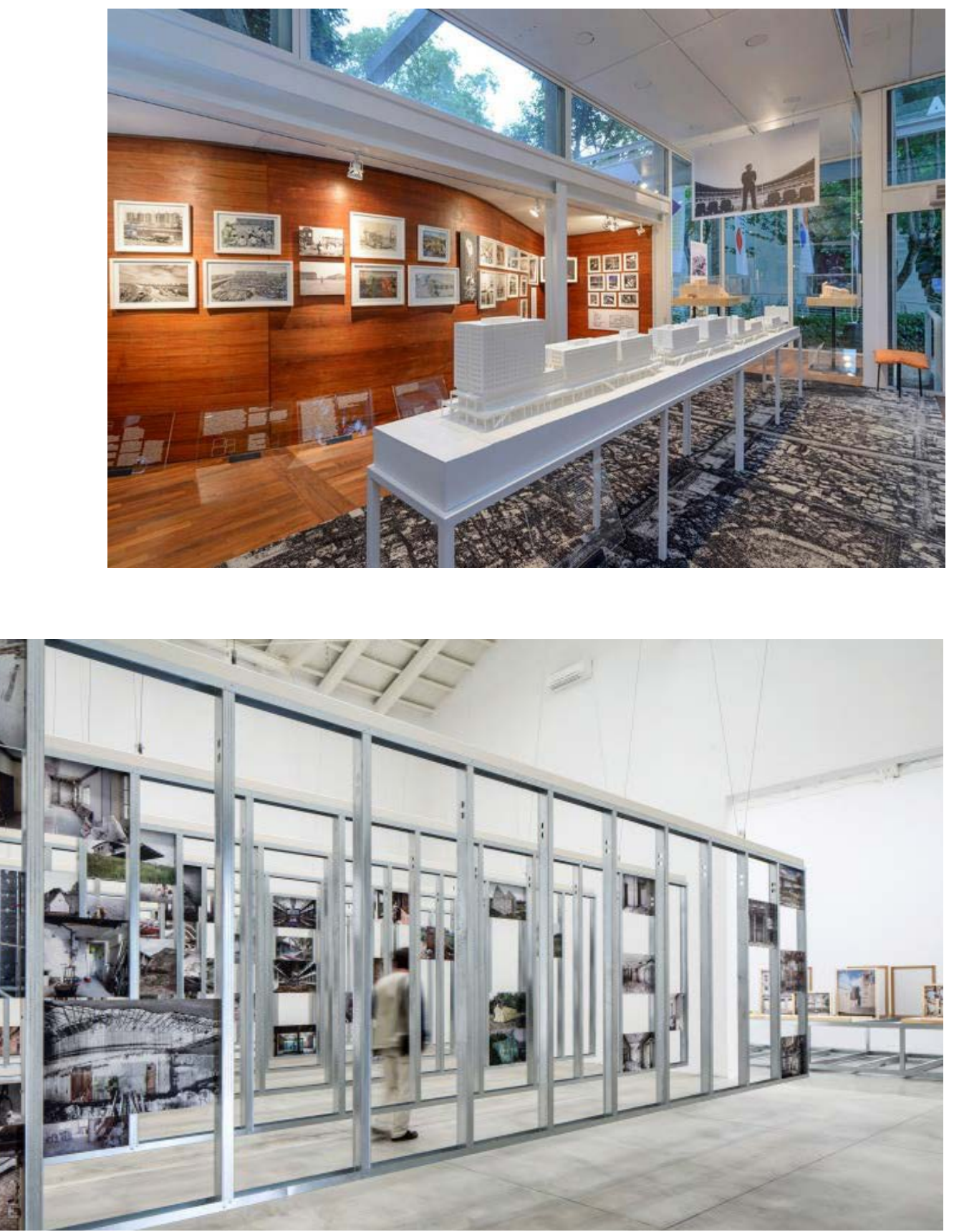

(A) Figura 7. Korea-Crow's Eye (4) View.

Nota: ganó el León de Oro como mejor participante nacional. "Un novedoso y rico cuerpo de conocimientos [...] es investigación en acción que expande la narrativa espacial y arquitectónica en la realidad geopolítica", cita: el jurado. Del pabellón no filtraba complacencia ni prejuicio.

Fuente: La Biennale di Venezia (2014b) @ .

(A) Figura 8. España ganó el (A) León de Oro en 2016 como mejor participante nacional, gracias a la exhibición de 55 proyectos que han imaginado un nuevo diseño para los restos no terminados de algunas de las obras de las más grandes empresas constructoras de la historia de España. Los arquitectos expresan desafío a esta condición de abandono. Fuente: Galli (2016) @

\section{Conformismo-desafío}

En la presentación de la bienal de 2014, el presidente Paolo Baratta expresa con fuerza cómo el principal intento de las bienales de los últimos años fue denunciar "la desconexión entre arquitectura y sociedad civil [y] el dualismo entre el exceso y la indiferencia [...] un peligro de conformismo, favorecido por la economía y la tecnología" (Baratta, 2014, p. 17). Utilizando estas palabras programáticas como hito, se intentará en este ulterior paralelo, ver las diferencias entre las dos bienales en relación con su actitud frente a los poderes políticos y económicos y frente a las posibilidades tecnológicas.

A pesar de un excelente y novedoso proyecto curatorial, Koolhaas parece traicionar parcialmente los intentos de oponerse a los excesos, a la indiferencia y a la desconexión entre arquitectura y sociedad civil. Casi paradójicamente, la bienal curada por Koolhaas resulta conformándose con las piedras angulares de la sociedad occidental y con su lectura de "la complejidad de la realidad sin complacencia o prejuicio". Su curaduría se inclina hacia la abstracción, el puro conocimiento y la suspensión del juicio; por lo tanto, parece perder el poder de definir hitos emblemáticos que desafíen el estatus quo ${ }^{8}$ (Goldberger, 2000) (figura 7).

La exposición de Aravena de 2016 resulta "más política que curatorial" (Kochen, 2016). Esta bienal se substancia de la atracción por la

(...) fenomenología de cuanto ha pasado en estos ejemplos positivos [...] como se han evidenciado y expresados los deseos y las necesidades, cuales los procedimientos lógicos, institucionales, jurídicos, políticos y administrativos que han inducido una demanda por la arquitectura y por lo tanto permitido a la arquitectura de encontrar soluciones además de las banales o autodestructivas. (Baratta, 2016)

La curaduría de Koolhaas muestra una desconexión total de los lugares reales, una visión atópica que prescinde y se desinteresa de las condiciones políticas, económicas y sociales. De acuerdo con ello, la relación con el poder económico y político resulta como un sustrato indiferente y aceptable en cuanto funcional para el crecimiento profesional del arquitecto, así como para las oportunidades que puede proporcionar para desarrollar investigaciones formales e individualistas.

No obstante lo anterior, por una acción proyectual que tienda a establecer relaciones profundas con los lugares, no es posible prescindir de un compromiso político y cultural. En las experiencias exhibidas por la bienal de Aravena, todas las especificidades de contexto —el contenido social, las constricciones burocráticas, las limitaciones políticas, los recursos económicos, el medioambiente, etc. - pasan a pertenecer a la caja de herramientas proyectuales, junto con las más estrictamente disciplinarias (Paredes, 2016, p. II). A su vez, todos los elementos técnicos y tecnológicos constituyen entidades manipulables para desafiar, de una forma u otra, las características económicas de los contextos. Se expresa con rigor y fuerza en las mismas palabras del curador Aravena su indolencia hacia los grandes capitales, que son "avaros e impacientes". El poder necesita controlar el desarrollo, y, por lo tanto, el "conservadorismo de la burocracia tiende a producir un ambiente banal, mediocre y aburrido" (Aravena, 2016, pp. 20-21). Este desafío se extiende casi automáticamente a la visión sustancialmente conformista que la sociedad tecnológica contemporánea ostenta en la vertiente de las posibilidades tecnológicas. Materiales sencillos y locales se presentan en la bienal de 2016 como posibles y eficaces alternativas a los materiales industriales consuetos, $y$, sobre todo, a los materiales novedosos, que, si bien traen consigo un valor de investigación y de innovación,

8 El mismo Koolhaas expresa con claridad su punto de vista al decir: "nunca vi tanta pobreza [...] y casi instantáneamente entendí que era imposible juzgar lo que veía. En alguna forma solo puedes aceptarlo como una realidad". Citado en (Ouroussoff, 2012). 
suelen a menudo carecer de integración y de sostenibilidad $^{9}$. Con extrema síntesis, como en un manifiesto contrapuesto a las tendencias preponderantes, Aravena propone "contra de la escasez: el ingenio [...] contra de la abundancia: la pertinencia" (2016, p. 19) (figura 8).

Esta quintaesencia de una actitud sostenible contrasta con el enfoque maximalista que se había presentado en la miscelánea de elementos presentados por Koolhaas en su curaduría. En sus mostradores cada tecnología está igualmente disponible, y la selección que el arquitecto puede hacer se basa, preponderantemente, en los recursos disponibles. La exhibición de Elementos de Arquitectura intenta reconstruir la historia de cada elemento de la construcción reuniendo "antiguas, pasadas, corrientes y futuras versiones" de dichos elementos en una visión evolucionista. La contemporánea era digital permite "niveles de control drásticamente mejorados", pero el mismo Koolhaas admite que, en general, no hemos todavía "ni siquiera empezado a confrontarnos con la vastedad en constante expansión de su potencial lado obscuro" (2014, p. 193).

La sostenibilidad, entonces, necesita volver a medirse en su conexión con el lugar y con la causa específica de la acción. Cuando hay escasez de recursos, no importa cuánta tecnología haya disponible, no hay otra forma de ser sustentable sino con el ingenio. La innovación regresa a un nivel metodológico sin perder su enfoque reformador y libera la disciplina de los innecesarios y limitantes prejuicios tecnológicos. "Un montón de barro, ladrillos, madera y bambú a la vista" comenta sobre la bienal de 2016, de forma casi despreciativa, una periodista estadounidense (Zeiger, 2016, p. VI), sin ver en su plenitud esos ejemplos virtuosos que presentaban una cumplida integración de elementos tecnológicos básicos, para conformar posibles y atrevidas soluciones a reales problemas logísticos, económicos, estéticos y, sin embargo, de identidad cultural.

\section{Excepcional-ordinario}

Como revela Juan José Kochen, arquitecto y académico mexicano,

\begin{abstract}
La Bienal de Aravena quiere identificar el progreso de la arquitectura con el de la gente. No busca reducir la cultura arquitectónica: busca erradicar su impostura y utilizarla como arma transformadora, no solo para un 5\% de edificios y lugares excepcionales. (Kochen, 2016, p. XV)
\end{abstract}

Gracias a la bienal de Aravena, la necesidad de un sinnúmero interminable de pequeñas intervenciones para una mayoría casi invisible y de pocos recursos se contraponen a pocas grandes

9 "Es la experiencia de trabajar con lo esencial, combinando construcciones tradicionales con ingenio y nuevas tecnologías la que pone por delante a Latinoamérica a la hora de aportar para el futuro" (Zabalbeascoa, 2016, p. XI).
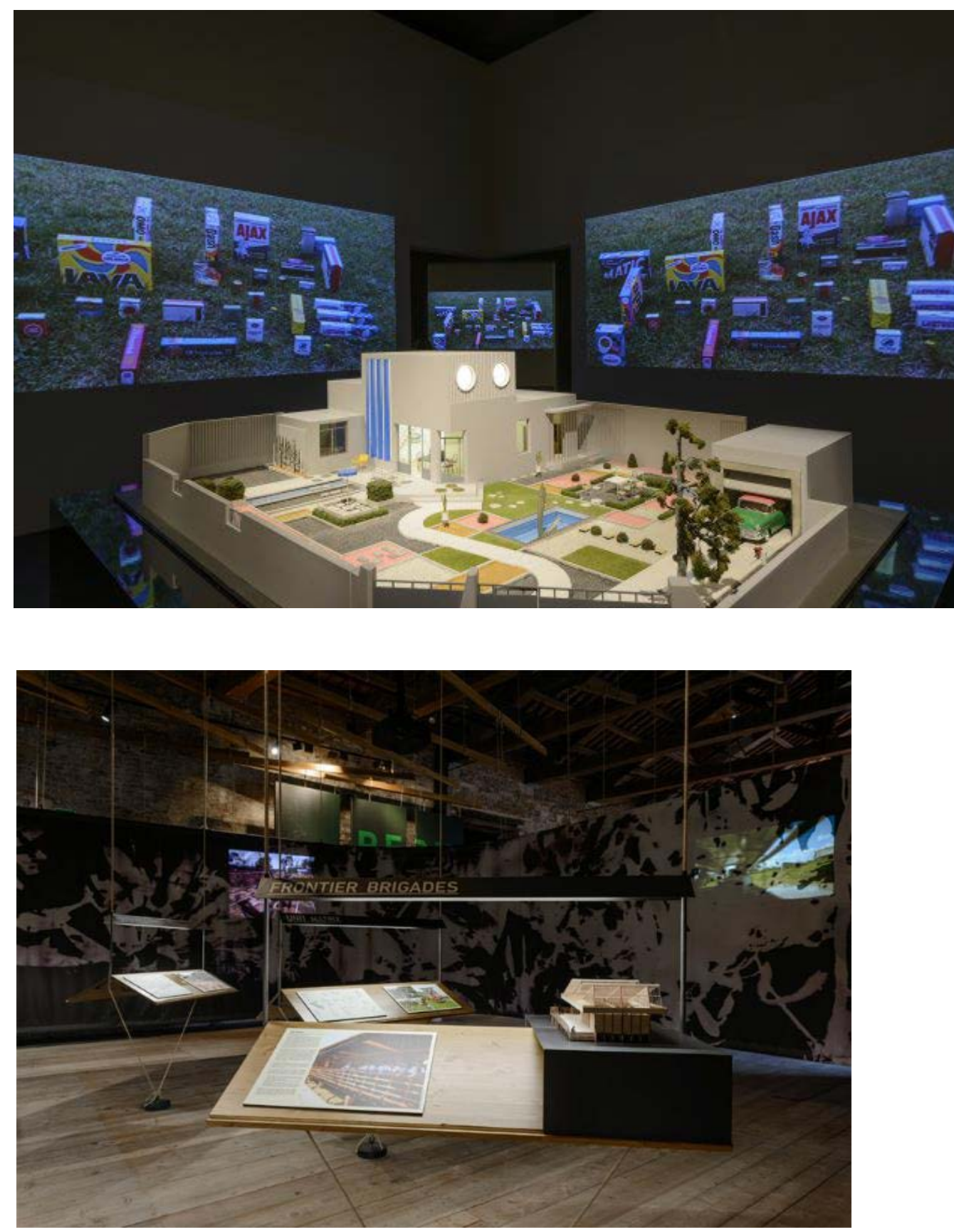

obras icónicas por unas minorías que emplean grandes capitales, y a las que se asigna mucha visibilidad mediática y, a menudo, didáctica.

Las muchas intervenciones necesarias para satisfacer las necesidades materiales y espirituales básicas de las mayorías tienen, inevitablemente, que enfrentarse con "la siempre amenazante escasez de recursos, las implacables restricciones, la falta de tiempo y la urgencia de cualquier tipo" (Aravena, 2016, p. 20). Las experiencias expuestas en la curaduría de Aravena demuestran una actitud antagónica frente a la impostación "aristocrática" de la curaduría de Koolhaas. A las grandes ideas novedosas se contrapone el "buen sentido común" y respecto a las ideas majestuosas, cuyo valor está solamente en su unicidad, se resucitan valores antiguos del hacer arquitectura. Ideas concretas, pequeñas, sometidas a procesos de revisión, evaluación e innovación, que, posiblemente, recuperen y perfeccionen elementos de la historia constructiva de las comunidades, balancean el equilibrio frente a ideas atrevidas e innovadoras que hoy en día raramente encarnan valores compartidos (figura 9).
A Figura 9. France-Modernity: (A) or menace? Nota: Mención especial del jurado por "analizar el suceso y los traumas conectados a las visiones de la modernidad" que se han generado en las ideas de los protagonistas franceses del movimiento moderno.

Fuente: Avezzù (2014) (C)

(A) Figura 10. Perú-Our A Amazon Frontline. Nota: mención especial del jurado, por "llevar la arquitectura en un rincón remoto del planeta, haciendo que esta sea tanto un lugar de aprendizaje como un medio para proteger la cultura de la amazona".

Fuente: Avezzù (2016) (C). 
Queda claro, por otra parte, que las ciudades son organismos arquitectónicos, y que en ellas las excepcionalidades instauran un continuo diálogo con los lugares ordinarios (Rossi, 1995). Esto, además de inevitable, es el presupuesto constructivo de la identidad colectiva. Es imprescindible, entonces, que la disciplina busque una síntesis eficaz para devolver la "excepcionalidad" a elementos primarios que se constituyan en vectores de la construcción de la identidad colectiva y no se queden como iconos del poder económico de pocos (figura 10).

Más allá del común despliegue sobre los problemas de las grandes ciudades, se debe abrir la visión a que muchas ciudades tienen todavía una escala menor, y a que muchísimas personas, especialmente en los países menos desarrollados, viven en pueblos más o menos desconectados (LafargeHolcim Foundation, 2016, p. II). Todo esto necesita atenciones e intervenciones proyectuales eficaces, por lo que se hacen necesarios nuevos ámbitos didácticos que preparen a los jóvenes arquitectos más allá de los estereotipos especulativos de las estrellas de la arquitectura mediática (Segre, 2015, p. 179).

\section{Autoría $^{\mathbf{1 0}}$-participación}

En Fundamentals, Koolhaas regresa a los básicos de la disciplina y conduce una introspección histórica erudita en los meandros del quehacer arquitectónico. Su bienal enfoca la mirada eminentemente hacia el pasado, y su actitud curatorial es de total autoría de las obras expuestas y de las áreas expositivas. "Koolhaas ha empleado el doble del tiempo normalmente empleado a investigar y desarrollar la muestra (dos años)"11 (Trafas, 2014, p. V). Su ejercicio de control de autor sobre la exhibición se ha alargado hasta redefinir la forma como las diversas componentes de la bienal dialogan entre sí. El arsenal, los jardines y el pabellón central han sido objeto de un diseño minucioso, que se ha ensanchado hasta definir un tema único para todos los participantes nacionales (Absorbing Modernity 19142014) (figura 11).

Reporting from the front se impone como una exhortación a que los arquitectos más comprometidos con situaciones complejas expongan sus obras y hagan de informar sobre su experiencia una prioridad, para que más personas estén al corriente de lo que hacen y, sobre todo, de cómo lo hacen. Esta exhortación por sí misma implica, por un lado, que la curaduría no pueda excederse en su autoría, la cual se limita, y eso no es poco, a ejercer el derecho de selección; $y$, por otro, que los arquitectos que exponen estén dispuestos a compartir sus métodos. Eso expone sus procesos y sus resultados a que puedan ser replicables, y por ello tienen que estar dispuestos a ver disminuir el valor de su autoría,

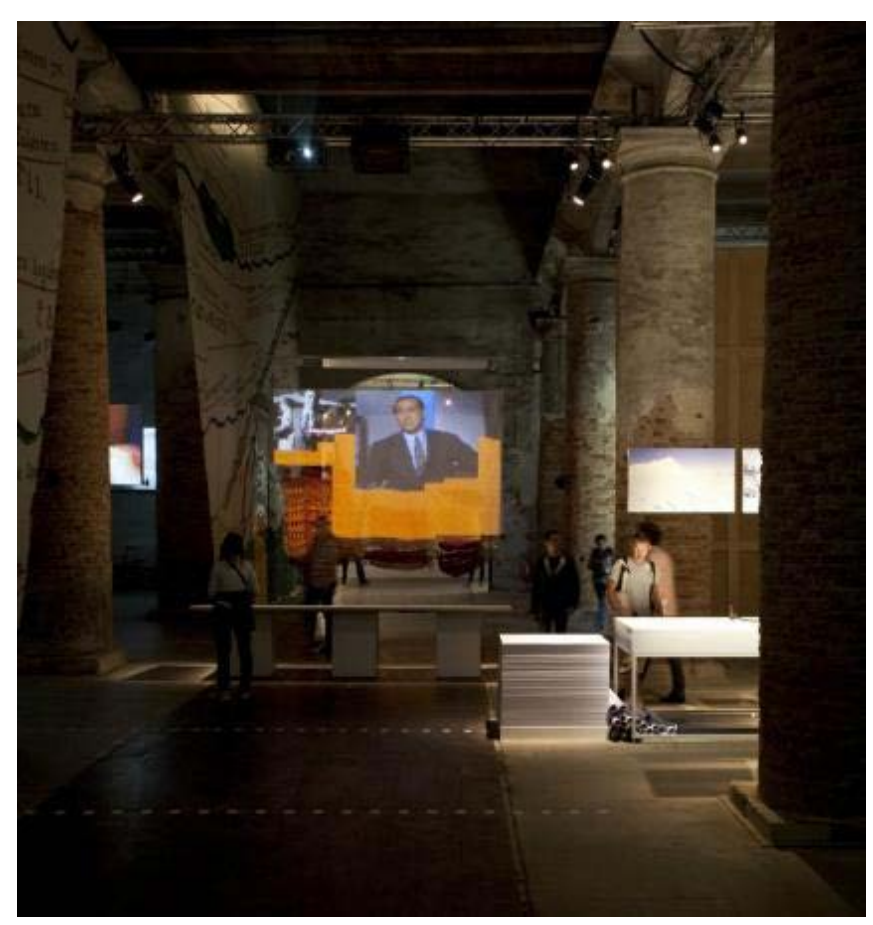

(A) Figura 11. Sales Oddity: Milano 2 and the Politics of Direct-to-home TV Urbanism.

Nota: León de plata para el mejor proyecto de investigación de la sección Monditalia. "El proyecto presenta [...] un

aspecto fundamental de las modernas sociedades [dominadas por la cultura neoliberal y tecnológica]: cómo el poder de los medios de comunicación ocupa otros espacios sociales, tanto física como políticamente" (Mora, 2014, párr. 4).

Fuente: Galli (2014c) (C)

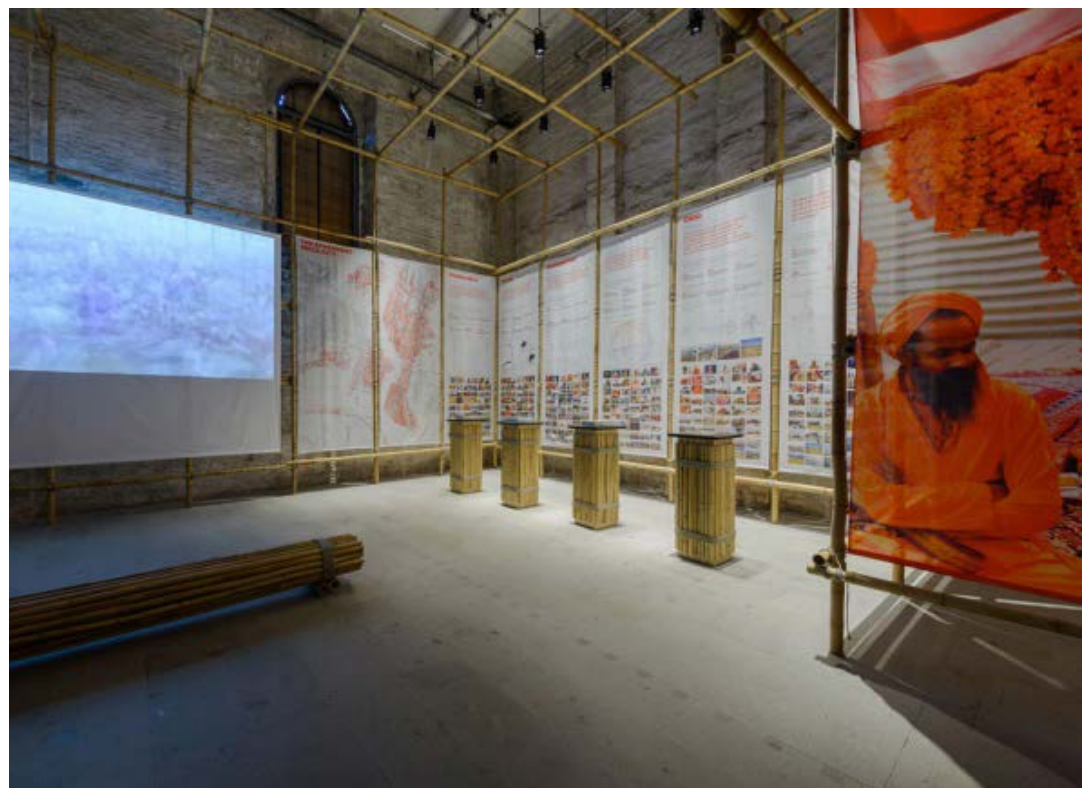

(A) Figura 12. Raúl Mehrotra y Felipe Vera.

Nota: Cada 12 años, más de 100 millones de personas se reúnen en la confluencia de los ríos Ganga y Yamuna, un lugar sagrado. La megaciudad de Kumbh Mela se crea en un par de semanas, y cuando llega un monzón se la lleva hasta no dejar rastro de ella. Es una arquitectura efímera, pero compleja y funcional.

Fuente: La Biennale di Venezia (2016b) (C) 
a cambio del aumento de las posibilidades de avance en la evolución de sus mismos métodos.

Las obras expuestas en la bienal de Aravena demuestran que la arquitectura en acción está llamada a responder a más de un problema a la vez, y, por lo tanto, hay que "ensanchar el ámbito de los asuntos [...] añadiendo a la dimensión cultural y artística, que ya se encuentran en nuestra esfera, las que son en el lado social, político, económico y medioambiental del espectro" (Aravena, 2016, p. 21). Al ensancharse los ámbitos, inevitablemente, tienen que corresponder un alargarse del factor tiempo y un abrirse a dinámicas de participación. Un solo "autor" no puede abarcar un espectro tan amplio: la arquitectura es una disciplina colectiva, y los logros difícilmente resultan ser individuales ${ }^{12}$. La variable tiempo surge claramente en la bienal de Aravena como factor determinante para la calidad del proyecto, verdadera herramienta de diseño, y no solo línea temporal hacia una fecha de entrega (figura 12).

La calidad, como lo demuestra, de hecho, el mismo tiempo empleado por Koolhaas en desarrollar su exposición, necesita tiempo, investigación, confrontación y cura. Al contrario, y desafortunadamente, la tendencia comercial contemporánea pide siempre más producto en menor tiempo, para poder generar más ganancia y más visibilidad. Dicha actitud aplasta la creatividad contra las necesidades del mercado ${ }^{13}$, y prueba de esto son las obras de muchas empresas internacionales de la construcción y de algunas estrellas de la arquitectura global contemporánea, que, finalmente, reducen sus novedades iniciales a estilos formales descontextualizados que no generan ningún legado de escuelas metodológicas (Ouroussoff, 2012, p. II).

En las experiencias vistas en la bienal de 2016, a una percepción "activa" del tiempo se asocia una temporalidad "pasiva"; es decir, se contempla la necesaria demora para la adquisición del producto arquitectónico por parte de la sociedad. A partir de ello se consideran las posibilidades proyectuales para facilitar esta reconexión, reconociendo las bases en los procesos humanos de participación que siempre han formado parte del proceso de constitución de la identidad. El proyecto se abre sobre estos principios a las interferencias de los procesos de participación, tema casi totalmente olvidado en las anteriores bienales, pero que, por el contrario, en 2016 juega un papel fundamental. La metodología participativa de diseño, y siquiera de construcción, gene-

12 Ver respuesta de Aravena al jurado del premio Pritzker en The Hyatt Foundation (2016, p. VII).

13 "La economía de Mercado ha erosionado el estatus mora de la arquitectura. Ha divorciado los arquitectos del público y empujados en los brazos del sector privado" (Koolhaas, 2014, p. 17). ra una arquitectura más permeable en su papel social, abre al intercambio entre los profesionales y los usuarios, al enfrentamiento entre los profesionales y las instituciones, y evita que las prerrogativas autorales sean antepuestas al objetivo por el que se ejerce la acción proyectual.

A través del proceso participativo, el proyecto se hace "más interesado a las fuerzas en juego [y] cuanta más fuerzas, cuanto menos la noción de autoría es reconocible" (Deam, 2017, p. 40). Se podría añadir que cuanto menos es reconocible la noción de autoría, tanto más susceptible es el objeto arquitectónico de formar parte de un contexto cultural compartido, libre de cargas autorales abrumadoras.

La "arquitectura en acción es una herramienta de la vida social y política" (Baratta, 2016, p. 15), y esta consciencia debería dejar atrás el miedo a la pérdida del valor artístico individual de la obra, para abrir la disciplina a sus reales potencialidades, con miras a generar escuelas metodológicas de gran escala, en vez de líneas estilísticas particulares. La abstracción intelectual tiene que vincularse al pragmatismo factual, y con esto, redefinir la actitud informativa y de intercambio de informaciones. Por ese rumbo, la disciplina podría acercarse mucho más a la actitud de las ciencias, en cuyos ámbitos los investigadores y los técnicos se confrontan con bases comunes, a fin de permitir que los éxitos sean replicables, y los fracasos, evitables.

\section{Conclusiones}

Estos cinco comparativos conceptuales, ejercidos sobre el cuerpo de las dos bienales, aclaran algunas de las diferencias disciplinarias que caracterizan los dos "hemisferios". ¿Cómo puede esto, a su vez, delinear tendencias de acción paralelas, para las que valdría auspiciar una convergencia?

Según el análisis desarrollado, las siguientes características definen de manera evidente dos tendencias globales en acción en los relativos ámbitos "hemisféricos" de influencia (tabla 1).

La nítida división, al menos en relación con los conceptos resaltados, entre los dos hemisferios "norte" y "sur" deja abierta una grieta inspiradora. Entender el valor de las experiencias recíprocas en el contexto global actual puede arrojar luz sobre las potencialidades del diálogo entre estas dos tendencias, que, casi como las dos mitades de un pomo, solo en su unión pueden reconstituir la verdadera complejidad artística y social de la disciplina.

Entender el contexto como un ámbito “común", sin intentar ver sus trascendencias a través de la abstracción, es igualmente limitante, por los valores disciplinarios, cuanto lo es una 
El contexto es una entidad que mantiene siempre un grado de abstracción en la determinación de las características y de las necesidades humanas.
El contexto es la realidad más común, más corriente y cotidiana; está vinculado al presente factual, a las condiciones ambientales y sociales.

\section{Composición}

\section{Proyecto}

Se asigna mayor valor a la componente artística de la disciplina, por lo que el estudio de las relaciones armónicas entre las partes asume un valor preminente.
Se valora la capacidad de resolver la mayor cantidad posible de problemas, con un diseño de arquitectura que haga converger todos los componentes multidisciplinarios.

\section{Conformismo}

Las complejidades de la realidad son asumidas sin complacencia ni juicio, y el estatus quo político/tecnológico es visto como una condición natural.
Las características de la sociedad no son asumidas como naturales, y se las cuestiona en el interior del ámbito disciplinar, en los aspectos políticos y en las variantes tecnológicas.
Excepcional

Gran parte del valor de una obra le viene asignado por su originalidad, sus componentes de innovación, su valor económico y su unicidad.

\section{Ordinario}

Se aprecian un resultado o un método más allá de su valor y de su originalidad, los cuales merece solo si proporciona soluciones innovadoras a problemas reales y puede replicarse.

\section{Autoría}

\section{Participación}

El autor es la entidad que concibe la idea, que ejerce el control y la influencia decisiva para su desarrollo y cuyo nombre está indisolublemente relacionado con la obra.
Participación, cooperación e intercambio emergen como palabras clave. El autor de una idea valora su difusión a fin de mejorarla, más que mantener la autoría.
A Tabla 1. Características de las dos tendencias globales; ámbitos "hemisféricos" de influencia y de acción. Fuente: elaboración propia (2018). reflexión totalmente destacada de los problemas reales, sociales y políticos. Un excesivo pragmatismo puede ser tan perjudicial como una visión excesivamente "encumbrada".

El proyecto, como método, existe por sí mismo, sin los principios básicos de la composición, pero no en el ámbito de la arquitectura. Al mismo tiempo, la composición pierde su valor artístico en arquitectura si no consigue, a la vez, responder a los problemas multidisciplinarios que se le plantean al ser llamada a cumplir con su papel de modificación del ambiente humano y natural. Claramente, no siempre el arte es un valor imprescindible al construir cosas y casas ordinarias; no obstante, sí es imprescindible comprender la relación entre ordinario y excepcional en la construcción de la identidad colectiva de las comunidades. Por esto sería provechoso un profundo intercambio entre los dos hemisferios, para complementar sus acciones, abrirse a la participación y a la reciprocidad, para no dejar atrás los valores más importantes que se reflejan en el organismo construido de las sociedades.

Sobre un solo concepto se auspicia que el equilibrio de los valores en juego pese más hacia una de las dos partes: el desafío. El contexto global actual, caracterizado por las grandes migraciones mundiales y por el cada día más frágil equilibrio medioambiental, pide con fuerza una profunda refundación que haga la disciplina más atenta a su impacto y más atrevida en su voluntad de desafiar los problemas que la contemporaneidad le sugiere (Arquitexto, 2016). Estas dificultades se revelan siempre más globales, y no solo hemisféricas, y la disciplina no puede ni pasivamente aceptarlas, ni activamente ignorarlas. Es indispensable e inevitable desafiarlas.

Indudablemente, en el auspiciado reequilibrio de las disparidades económicas y tecnológicas globales será necesaria la consciencia de que la sostenibilidad es un concepto sintético y holístico, al que deben pertenecer valores básicos de identidad, de producción material, de estructura y organización social, de relaciones políticas y de difusión de los conocimientos técnicos-científicos. Por esto, quizás, los países donde los recursos son más limitados, y los desafíos, más complejos, sean los que mejor puedan enseñar el camino para desafiar el actual estado de las cosas y lograr una sostenibilidad integral contraponiendo la pertinencia a la abundancia. 


\section{Referencias}

Al Borde Arquitectos. (2016). Al Borde-Dark Resources [Archivo propio]. Recuperado de:

\section{http://www.albordearq.com/}

Aravena, A. (2016). Rationale. En Fondazione la Biennale di Venezia, Mostra Internazionale di Architettura: Reporting from the Front, Biennale Architettura (pp. 19-23). Venezia: Marsilio.

Aravena, A. (Ed). (2002). El lugar de la arquitectura. Chile: Pontificia Universidad Católica de Chile: Ediciones ARQ Facultad de Arquitectura, Diseño y Estudios Urbanos.

Arquitexto. (2016). Bienal de Arquitectura de Venecia 2016. Arquitexto [Mensaje en un blog].Recuperado de:

https://arquitexto.com/2016/10/bienalarquitectura-venecia-2016/

Avezzù, A., (2016) [Fotografías de La Biennale di Venezia] Biennale Architettura 2016, ingresso/entrance [Archivo propio].

Avezzù, A., (2014) [Fotografías de La Biennale di Venezia] Perú - Our Amazon Frontline [Archivo propio].

Baratta, P. (2014). Introduction. En Fondazione la Biennale di Venezia Fundamentals Catalogue, 14. Mostra internazionale di architettura (pp. 14-15). Venezia: Marsilio.

Baratta, P. (2016). Introduction. En Fondazione la Biennale di Venezia, Mostra Internazionale di Architettura: Reporting from the Front, Biennale Architettura (pp. 14-18). Venezia: Marsilio.

Chatel, M. (27 de junio de 2016). Critical RoundUp: Did Aravena's 2016 Venice Biennale Achieve its Lofty Goals? ArchDaily. Recuperado de:

https://www.archdaily.com/790218/criticalround-up-did-aravenas-2016-venicebiennale-achieve-its-lofty-goals

Cheng, L. (1 de agosto de 2016). Reporting from the Front or an affront to architecture? ArchitectureAU Architecture Media [Mensaje en un blog]. Recuperado de: https://architectureau.com/articles/ reporting-from-the-front-or-an-affront-toarchitecture/

Davies, C. (2011). Thinking about architecture. An introduction to architectural theory. London: Laurence King Publishing.

Deam, L. (2017). Modern world conversation. Alejandro Aravena. Dwell Magazine (07), pp. 40-42. Recuperado de: http://www.elementalchile.cl/wp-content/ uploads/2017/08/170701 DWELL MAGAZINE CONVERSATION_ALEJANDRO_AR̄AVENA.pdf

Fajardo, M., \& Oliveros, T. (16 septiembre de 2015). La mirada social de Alejandro Aravena, el primer chileno en dirigir la prestigiosa Bienal de Venecia 2016 de Arquitectura. El Mostrador [periódico en línea]. Recuperado de:

https://www. elmostrador.cl/ cultura/2015/09/16/la-mirada-social-dealejandro-aravena-el-primer-chileno-endirigir-la-prestigiosa-bienal-de-venecia2016-de-arquitectura/

Frearson, A. (23 de febrero de 2016). Aravena rounds up architecture's biggest names for Venice Biennale 2016. Dezeen [Revista en línea]. Recuperado de: https://www.dezeen.com/2016/02/23/ architects-participating-venice-architecturebiennale-2016-alejandro-aravena/

Galli, F. (2014a). [Fotografías de La Biennale di Venezia] Soffitto-Padiglione Centrale-Giardini [Archivo propio].

Galli, F. (2014b). [Fotografías de La Biennale di Venezia] Folder-Italian Limes [Archivo propio].

Galli, F. (2014c). [Fotografías de La Biennale di Venezia] Andrés Jaque Ovejero, Office for Political Innovation-Corderie-Arsenale [Archivo propio].

Galli, F. (2016). [Fotografías de La Biennale di Venezia] Pabellón Español [Archivo propio].

Goldberger, P. (2000). The Architecture of Rem Koolhaas. The Hyatt Foundation [Ensayo]. Recuperado de:

https://www.pritzkerprize.com/sites/default/ files/inline-files/2000_essay.pdf

Horton, G. (20 de junio de 2014). Of Fundamentals and Fundamentalists: Critics Talk Koolhaas's Biennale. Metropolis [Mensaje en un blog]. Recuperado de:

https://www.metropolismag.com/architecture/ of-fundamentals-and-fundamentalists-criticstalk-koolhaass-biennale/

Kochen, J. J. (12 de julio de 2016). Una bienal más política que curatorial: 17 lecciones de la Bienal de Venecia 2016. ArchDaily. Recuperado de:

https://www.plataformaarquitectura.cl/ cl/791045/una-bienal-mas-politica-quecuratorial-17-lecciones-de-la-bienal-devenecia-2016

Koolhaas, R. (2014). Elements of Architecture, Monditalia, Absorbing Modernity 19142014. En Fondazione la Biennale di Venezia, Fundamentals Catalogues, 14. Mostra internazionale di architettura (pp. 17-22/193194). Venezia: Marsilio.

La Biennale di Venezia. (2014a). [Fotografías de La Biennale di Venezia] Biennale Architettura 2014-Fundamentals [Archivo propio].

La Biennale di Venezia. (2014b). [Fotografías de La Biennale di Venezia] Republic of KoreaCrow's Eye View: The Korean Peninsula [Archivo propio].

La Biennale di Venezia. (2016a). [Fotografías de La Biennale di Venezia] Gabinete de arquitectura-Rompiendo el sitio [Archivo propio].

La Biennale di Venezia. (2016b). [Fotografías de La Biennale di Venezia] Rahul Mehrotra, Felipe Vera-Ephemeral Urbanism: Cities in Constant Flux [Archivo propio].

LafargeHolcim Foundation. (26 noviembre de 2016). How can people care about sustainability, when they have no security. LafargeHolcim Foundation [mensaje en un blog]. Recuperado de http://www.lafargeholcimfoundation.org/Article/how-can-peoplecare-about-sustainability-with-no-security

Mora, P. (4 de julio de 2014). Bienal de Venecia 2014: SALES ODDITY/Andrés Jaque, León de Plata Mejor Proyecto de Investigación. Recuperado de: https://www.archdaily.co/co/623405/bienalde-venecia-2014-sales-oddity-andresjaque-leon-de-plata-mejor-proyecto-deinvestigacion
Ouroussoff, N. (septiembre de 2012). Why is Rem Koolhaas the World's Most Controversial Architect? Smithsonian.com. [Mensaje en un blog].Recuperado de:

https://www.smithsonianmag.com/arts-culture/ why-is-rem-koolhaas-the-worlds-mostcontroversial-architect-18254921/

Paredes, S. (2016). Opinión-Urgencia y Optimismo: acerca de la 15a bienal de Venecia. Revista ARQ. [Arq ediciones]. Recuperado de: http://www.edicionesarq.cl/2016/urgenciay-optimismo-bienal-de-venecia-2016/

Rossi, A. (1995). L'architettura della città. Torino: Città Studi.

Segre, R. (2015). Arquitectura y urbanismo. Cuba y América Latina desde el siglo XXI. La Habana: Editorial Arte y Literatura.

Stott, R. (10 de junio de 2014). Critical Round-Up: Venice Biennale 2014. ArchDaily. Recuperado de:

https://www.archdaily.com/514611/criticalround-up-venice-biennale-2014

Taylor-Hochberg, A. (19 de junio de 2014). Archinect rounds up critical reactions to Koolhaas Biennale. Archinect [Mensaje en un blog]. Recuperado de:

h t tps: //archinect.com/n ews/ article/102190685/archinect-rounds-upcritical-reactions-to-koolhaas-biennale

The Hyatt Foundation. (13 de enero de 2016 enero 13). Alejandro Aravena of Chile receives the 2016 Pritzker Architecture Prize. The Pritzker Architecture Prize [Mensaje en sitio web]. Recuperado de:

https://www.pritzkerprize.com/ announcement-ale-jan-dro-ara-ve-na

Trafas, Z. (18 de junio de 2014). Fundamentals: Venice Architecture Biennale. Apollo Magazine. Recuperado de:

https://www.apollo-magazine.com/ fundamentals-venice-architecture-biennale/

Ultimahora. (2016). Solano Benítez gana el León de Oro en la Bienal de Venecia. Ultimahora [Periódico en línea]. Recuperado de: https://www.ultimahora.com/solano-benitezgana-el-leon-oro-la-bienal-venecia-n995233.html

Vaisman, R. (julio de 2016). Bienal de Arquitectura de Venecia: la trinchera de la realidad. Cosas [Mensaje en un blog]. Recuperado de:

https://cosas.pe/cultura/23450/bienal-dearquitectura-de-venecia/

Zabalbeascoa, A. (26 de mayo de 2016). Una bienal latina y a escala humana. El País.

Recuperado de:

https://elpais.com/cultura/2016/05/26/ actualidad/1464291361_789539.html

Zeiger, M. (junio de 2016). Is architecture really as guileless Aravena's Biennale suggests? Dezeen. Recuperado de:

https://www.dezeen.com/2016/06/01/ opinion-mimi-zeiger-venice-architecturebiennale-2016-honest-fronting/ 


\section{Vol.}
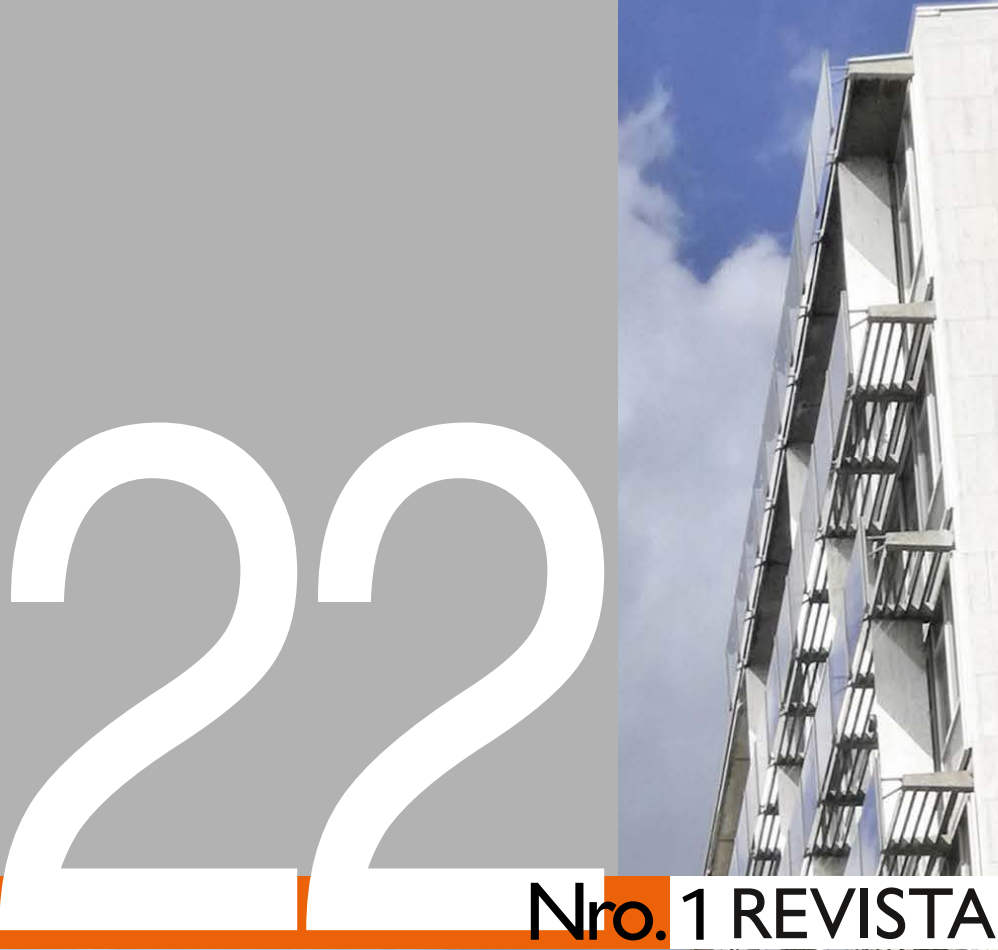

ISSN: 1657-0308 (Impresa)

Nro. 1 REVISTA DE ARQUITECTURA

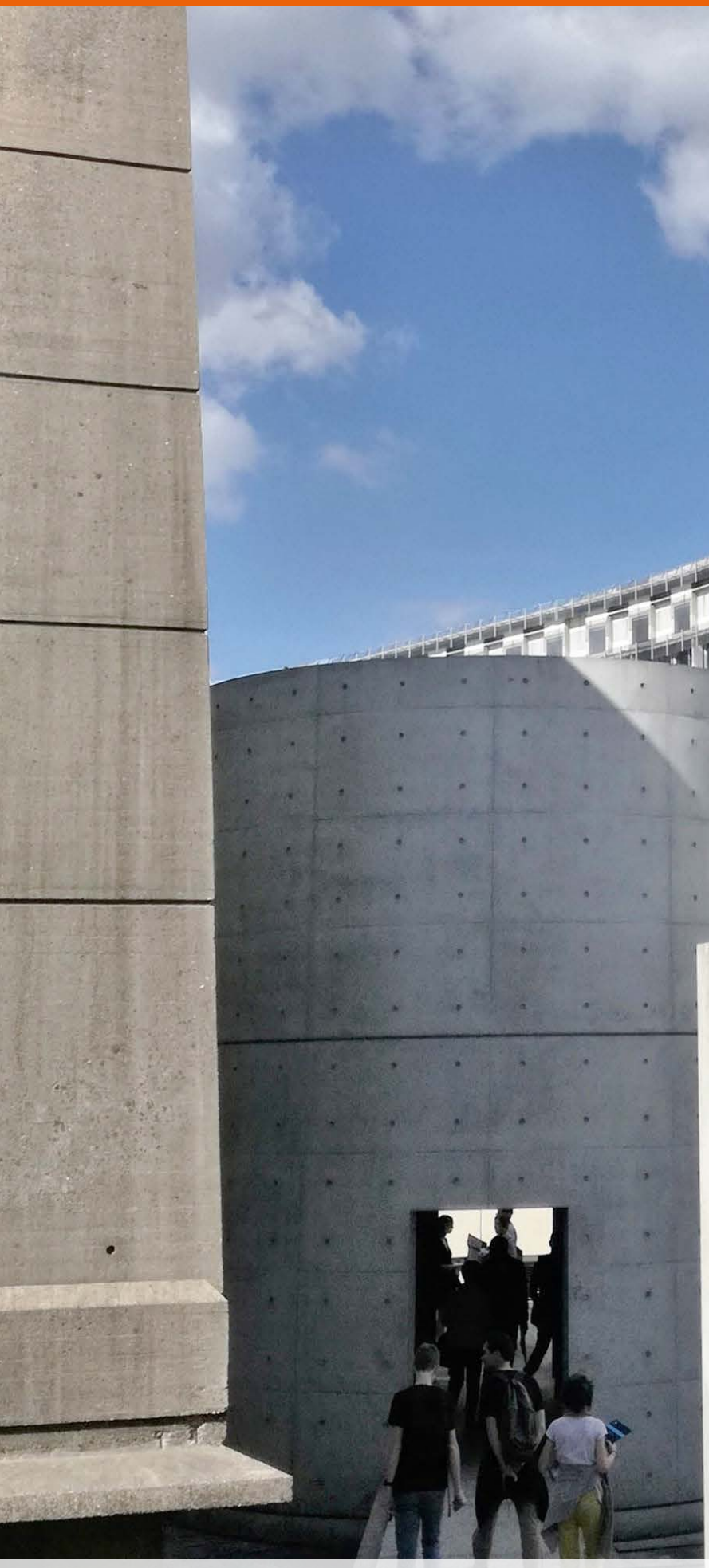

$\overline{9}$
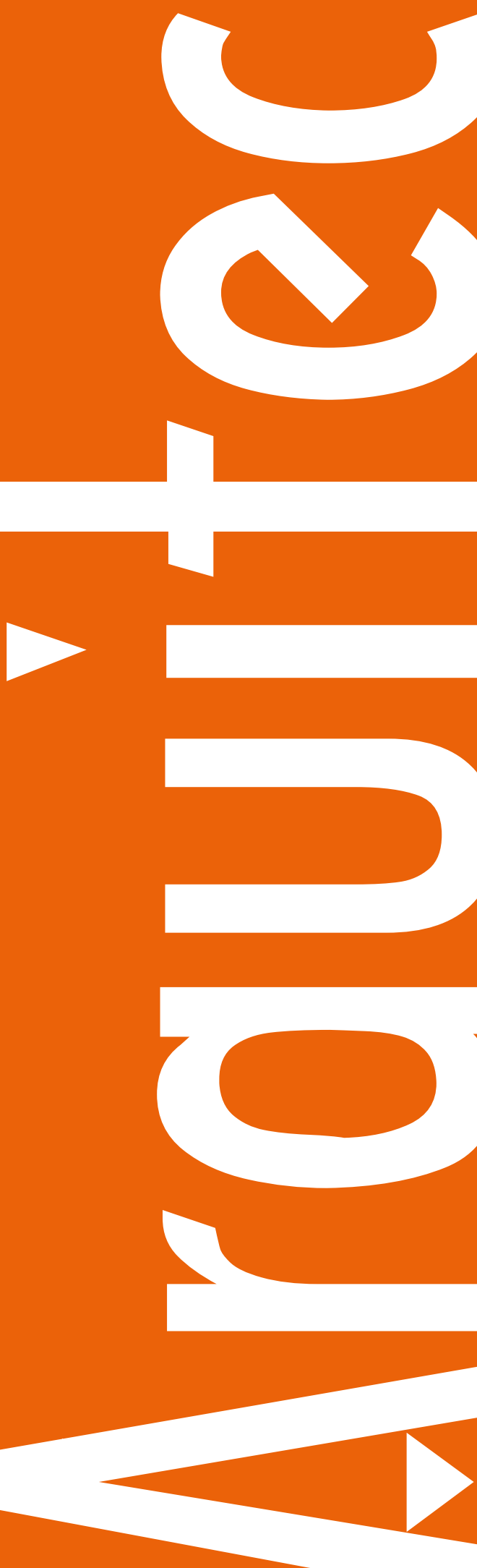


\section{Enfoque y alcance}

La Revista de Arquitectura (Bogotá) ( (ISSN 1657-0308 Impresa y E-ISSN 2357-626X en línea) es una publicación científica seriada de acceso abierto, arbitrada mediante revisión por pares (doble ciego) e indexada, en donde se publican resultados de investigación originales e inéditos.

Está dirigida a la comunidad académica y profesional de las áreas afines a la disciplina. Es editada por la Facultad de Diseño y el Centro de Investigaciones (CIFAR) de la Universidad Católica de Colombia en Bogotá (Colombia).

La principal área científica a la que se adscribe la Revisto de Arquitectura (Bogotá) según la OCDE es:

Gran área: 6. Humanidades

Área: 6.D. Arte

Disciplina: 6D07. Arquitectura y Urbanismo

También se publican artículos de las disciplinas como 2A02, Ingeniería arquitectónica; 5C03, Estudios urbanos (planificación y desarrollo); 6D07, Diseño.

Los objetivos de la Revista de Arquitectura (Bogotá) son:

- Promover la divulgación y difusión del conocimiento generado a nivel local, nacional e internacional

- Conformar un espacio para la construcción de comunidades académicas y la discusión en torno a las secciones definidas.

- Fomentar la diversidad institucional y geográfica de los autores que participan en la publicación.

- Potenciar la discusión de experiencias e intercambios científicos entre investigadores y profesionales.

- Contribuir a la visión integral de la arquitectura, por medio de la concurrencia y articulación de las secciones mediante la publicación de artículos de calidad.

- Publicar artículos originales e inéditos que han pasado por revisión de pares, para asegurar que se cumplen las normas éticas, de calidad, validez científica, editorial e investigativa.

- Fomentar la divulgación de las investigaciones y actividades desarrolladas en la Universidad Católica de Colombia.
Palabras clave de la Revista de Arquitectura (Bogotá): arquitectura, diseño, educación arquitectónica, proyecto y construcción, urbanismo.

Idiomas de publicación: español, inglés, portugués y francés. Título abreviado: Rev. Arquit.

\section{Titulo corto: RevArq}

\section{Políticas de sección}

La revista se estructura en tres secciones correspondientes a las líneas de investigación activas y aprobadas por la institución, y dos complementarias, que presentan dinámicas propias de la Facultad de Diseño y las publicaciones relacionadas con la disciplina.

Cultura y espacio urbano. En esta sección se publican los artículos que se refieren a fenómenos sociales en relación con el espacio urbano, atendiendo aspectos de la historia, el patrimonio cultural y físico, y la estructura formal de las ciudades y el territorio.

Proyecto arquitectónico y urbano. En esta sección se presentan artículos sobre el concepto de proyecto, entendido como elemento que define y orienta las condiciones proyectuales que devienen en los hechos arquitectónicos o urbanos, y la forma como estos se convierten en un proceso de investigación y nuevo de conocimiento. También se presentan proyectos que sean resultados de investigación, los cuales se validan por medio de la ejecución y transformación en obra construida del proceso investigativo. También se contempla la publicación de investigaciones relacionadas con la pedagogía y didáctica de la arquitectura, el urbanismo y el diseño.

Tecnología, medioambiente y sostenibilidad. En esta sección se presentan artículos acerca de sistemas estructurales, materiales y procesos constructivos, medioambiente y gestión, relacionados con los entornos social-cultural, ecológico y económico.

Desde la Facultad. En esta sección se publican artículos generados en la Facultad de Diseño, relacionados con las actividades de docencia, extensión, formación en investigación o internacionalización, las cuales son reflejo de la dinámica y de las actividades realizadas por docentes, estudiantes y egresados; esta sección no puede superar el $20 \%$ del contenido.

Textos. En esta sección se publican reseñas, traducciones y memorias de eventos relacionados con las publicaciones en Arquitectura y Urbanismo.
A Frecuencia de publicación

Desde 1999 y hasta el 2015, la Revista de Arquitectura (Bogotá) publicó un volumen al año, a partir del 2016 se publicarán dos números por año en periodo anticipado, enero-junio y julio-diciembre, pero también maneja la publicación anticipada en línea de los artículos aceptados (versión Post-print del autor).

La Revista de Arquitectura (Bogotá) se divulga mediante versiones digitales (PDF, HTML, EPUB, XML) e impresascon un tiraje de 700 ejemplares, los tiempos de producción de estas versiones dependerán de los cronogramas establecidos por la editorial.

Los tiempos de recepción-revisión-aceptación pueden tardar entre seis y doce meses dependiendo del flujo editorial de cada sección y del proceso de revisión y edición adelantado.

Con el usuario y contraseña asignados, los autores pueden ingresar a la plataforma de gestión editorial y verificar el estado de revisión, edición o publicación del artículo.

\section{A Canje}

La Revista de Arquitectura (Bogotá) está interesada en establecer canje con publicaciones académicas, profesionales o científicas del área de Arquitectura y Urbanismo, como medio de reconocimiento y discusión de la producción científica en el campo de acción de la publicación.

\section{Mecanismo}

Para establecer canje por favor descargar, diligenciar y enviar el formato: RevArq FP20 Canjes
Universidad Católica de Colombia (2020, enero-junio). Revista de Arquitectura (Bogotá), 22(I) I-188. Doi: 10.14718

ISSN: 1657-0308 E-ISSN: 2357-626X

Especificaciones:

Formato: $34 \times 24 \mathrm{~cm}$

Papel: Mate $115 \mathrm{~g}$

Tintas: Negro y policromía
A Contacto

Dirección postal:

Avenida Caracas No. 46-72.

Universidad Católica de Colombia

Bogotá D.C.(Colombia)

Código postal: 111311

Facultad de Diseño Centro de Investigaciones (CIFAR). Sede El Claustro. Bloque " $\mathrm{L}$ ", 4 piso Diag. 46A No. $15 \mathrm{~b}-10$ Editor, Arq. César Eligio-Triana

Teléfonos:

+57 (1) $3277300-3277333$

Ext. 3109; 3112 o 5146

Fax: +57 (1) 2858895
Correo electrónico: revistadearquitectura@ucatolica.edu.co cifar@ucatolica.edu.co

Página WEB: www.ucatolica.edu.co vínculo Revistas científicas

http://publicaciones.ucatolica.edu.co revistas-cientificas http://editorial.ucatolica.edu.co/ojsucatolica/revistas ucatolica/index.php/RevArq 
